\title{
Adipocytes release a soluble form of VAP-1/SSAO by a metalloprotease-dependent process and in a regulated manner
}

\author{
A. Abella ${ }^{1}$ S. García-Vicente ${ }^{1} \cdot$ N. Viguerie $^{2} \cdot$ A. Ros-Baró ${ }^{1} \cdot$ M. Camps ${ }^{1} \cdot$ M. Palacín ${ }^{1} \cdot$ A. Zorzano $^{1} \cdot$ L. Marti $^{1}$ \\ ${ }^{1}$ Barcelona Science Parc and Department of Biochemistry and Molecular Biology, Faculty of Biology, Universitat de Barcelona, \\ Barcelona, Spain \\ ${ }^{2}$ Research Unit on Obesity, French Institute of Health and Medical Research Unit 586, Louis Bugnard Institut, Rangueil Hospital, \\ Université Paul Sabatier, Toulouse, France
}

\section{Abstract}

Aims/hypothesis. Vascular adhesion protein-1 (VAP1), which is identical to semicarbazide-sensitive amine oxidase (SSAO), is a dual-function membrane protein with adhesion properties and amine oxidase activity. A soluble form of VAP-1 is found in serum, where concentrations are enhanced in diabetes and obesity. In vitro, soluble VAP-1 enhances lymphocyte adhesion to endothelial cells, thus possibly participating in the enhanced lymphocyte adhesion capacity that is implicated in the cardiovascular complications associated with diabetes or obesity. In both, the tissue origin of the soluble VAP-1/SSAO is unknown. We examined whether adipose tissue, which has abundant expression of VAP-1/SSAO, is a source of soluble VAP-1.

Methods. We detected VAP-1/SSAO in plasma of diabetic animals, with or without VAP-1 immunoprecipitation, and in culture medium from 3T3-L1 adipocytes and human adipose tissue explants. VAP-1 protein glycosylation was measured.
Results. Diabetic and obese animals have increased plasma SSAO activity associated with VAP-1 protein. We also found that 3T3-L1 adipocytes and human adipose tissue explants release a soluble form of VAP$1 / \mathrm{SSAO}$, which derives from the membrane. The release of soluble VAP-1 was enhanced by exposure of murine and human adipocytes to TNF- $\alpha$ and blocked by batimastat, a metalloprotease inhibitor. Partial ablation of adipose tissue reduced plasma SSAO activity in normal and diabetic rats.

Conclusions/interpretation. Adipose cells are a source of soluble VAP-1/SSAO released by shedding of the membrane form. The release of SSAO is regulated by TNF- $\alpha$ and insulin. By releasing VAP-1/SSAO, adipose cells could contribute to the atherogenesis and vascular dysfunction associated with diabetes and obesity. [Diabetologia (2004) 47:429-438]

Keywords Semicarbazide-sensitive amine oxidase Vascular-adhesion protein-1 $\cdot 3 \mathrm{~T} 3-\mathrm{L} 1 \cdot$ Human adipocytes $\cdot$ Metalloprotease $\cdot$ TNF- $\alpha$
Received: 28 July 2003 / Revised: 15 December 2003

Published online: 13 February 2004

C) Springer-Verlag 2004

L. Marti (๘)

Barcelona Science Parc and Department of Biochemistry and Molecular Biology, Faculty of Biology,

Universitat de Barcelona, Josep Samitier, 1-5,

08028 Barcelona, Spain

E-mail: 1marti@bio.ub.es

Abbreviations: SSAO, Semicarbazide-sensitive amine oxidase $\cdot$ VAP-1, vascular adhesion protein-1 .

sVAP-1/SSAO, soluble VAP-1/SSAO - VCAM-1, vascular cell adhesion molecule-1 $\cdot$ FBS, fetal bovine serum .

PMSF, phenylmethylsulfonylfluoride - DTT, dithiothreitol · SPARC, secreted acidic cysteine-rich protein

A. Abella and S. García-Vicente contributed equally to this work
Inflammatory diseases like atherosclerosis or diabetes adhesion molecules are up-regulated on the vascular endothelium at inflammation sites and mediate a multi-step adhesive process leading to the transmigration of leucocytes from the circulation into inflamed tissues [1,2].

In addition to membrane-bound adhesion molecules, soluble isoforms have been detected in the plasma of healthy persons $[3,4,5]$. Increased concentrations of such soluble adhesion molecules have been associated with atherosclerosis [3, 6, 7], Type 1 diabetes $[8,9,10]$, Type 2 diabetes $[11,12,13]$, hypertension [6], hyperlipidaemia [14] and cardiovascular diseases $[15,16]$. The concentrations of soluble adhesion molecules in blood could simply reflect endothelial inflammation or activation and increased expression 
on the endothelial surface. However, these soluble adhesion molecules also: (i) mediate angiogenesis, e.g. Eselectin, vascular cell adhesion molecule-1 (VCAM-1) [17]; (ii) modulate autoimmune inflammatory reactions that lead to Type 1 diabetes (intercellular adhesion molecule-1) [10, 17]; (iii) stimulate endothelial cell migration (sVCAM-1, E-selectin) [9]; (iv) exert procoagulant activity (P-selectin) [18]; or (v) increase lymphocyte binding, e.g. glycosylation-dependent cell adhesion molecule-1, vascular adhesion protein-1 (VAP-1) [4, 19]. All these events have been implicated in cardiovascular conditions such as atherosclerosis, angiopathy or retinopathy, which are associated with diabetes and obesity $[20,21]$.

Vascular adhesion protein-1 mediates lymphocyte adhesion to endothelial cells in a manner dependent on sialic acid [22]. VAP-1 is identical to semicarbazide-sensitive amine oxidase (SSAO) (EC 1.4.3.6) $[23,24]$. The soluble form of VAP-1/SSAO (sVAP$1 / \mathrm{SSAO}$ ) is found in the serum of healthy adults in the range of 50 to $140 \mathrm{ng} / \mathrm{ml}$ and is increased in inflammatory liver diseases [4], cardiovascular pathologies [25], endstage renal disease [26], obesity [27, 28], Type 1 diabetes $[27,29,30,31,32]$ and Type 2 diabetes $[27,31,33]$. The membrane form of VAP-1/SSAO is highly expressed in endothelial cells, smooth muscle cells and adipose cells, which are strongly implicated in the pathology of atherosclerosis. It has been proposed that the increase in circulating VAP-1/SSAO participates in the cardiovascular complications associated with diabetes and obesity. The soluble form of VAP-1/SSAO enhances the binding capacity of lymphocytes to endothelial cells [4] presumably through a lymphocyte pre-activation signal. In addition, it is possible that aldehydes like formaldehyde or methylglyoxal, which are products of the reaction catalysed by SSAO, generate protein cross-linking or the AGE implicated in atherogenic lesions, retinopathy and angiopathy, all of which are associated with diabetes.

In diabetes, the mechanisms and effectors involved in the shedding of sVAP-1/SSAO are unknown. In chronic liver disease it has been proposed that sVAP$1 / \mathrm{SSAO}$ is derived from the liver [34]. Due to the central role of adipose tissue in diabetes [35] and the fact that SSAO is highly expressed at the surface of adipocytes [36, 37, 38], we tested whether adipocytes release a soluble form of VAP-1/SSAO in a regulated way, and evaluated SSAO activity in plasma of GotoKakizaki rats (a model of Type 2 diabetes), in streptozotocin-induced diabetic mice and in non-diabetic obese Zucker rats. The presence of VAP-1/SSAO activity and protein was evaluated in the medium of 3T3-L1 adipocytes and human adipose tissue explants cultured in the absence or presence of TNF- $\alpha$. We also assessed the effect of surgical mass reduction of adipose tissue on plasma SSAO activity in control and diabetic rats.

\section{Materials and methods}

Chemicals. We procured $\left[{ }^{14} \mathrm{C}\right]$ benzylamine $(2180 \mathrm{GBq} / \mathrm{mmol})$ from Amersham Pharmacia Biotech (Arlington Heights, Ill., USA). Purified porcine insulin was a kind gift from Eli Lilly (Indianapolis, Ind., USA). Streptozotocin, semicarbazide hydrochloride, benzylamine hydrochloride and other chemicals were purchased from Sigma Aldrich (St. Louis, Mo., USA). Penicillin, streptomycin and gentamycin were purchased from InVitrogen (Carlsbad, Calif., USA). Murine and human TNF- $\alpha$ and leptin were from Peprotech (London, UK). Batimastat (BB94) was a kind gift from J. Arribas (Hospital Vall d'Hebron, Barcelona, Spain). All electrophoresis reagents and molecular weight markers were obtained from Bio-Rad (Hercule, Calif., USA). Enhanced chemiluminescence reagents (super signal substrate) were from Amersham. Vibrio cholera neuraminidase (sialidase) was from Boehringer Mannheim (Mannheim, Germany) and N-glycosidase F from New England Biolabs (Beverly, Mass., USA). Monoclonal anti-VAP1/SSAO antibodies, TK10-79 and TK7-88, were a gift from Dr. S. Jalkanen (Biocity, University of Turku, Finland). Polyclonal anti-SSAO antibody was provided by Dr. M. Unzeta. Polyclonal anti-GLUT4 antibody (OSCRX) was produced from rabbit as reported previously [39]. Polyclonal anti-caveolin-1 antibody was from Santa Cruz Biotechnology (Santa Cruz, Calif., USA). Amicon Centriprep and Centricon were from Millipore (Bedford, Mass., USA).

Animals. Male Wistar rats weighing 180 to $220 \mathrm{~g}$, Swiss mice weighing 20 to $25 \mathrm{~g}$, 3-month-old Zucker lean rats (Fa/?) weighing $224 \pm 7 \mathrm{~g}$ and obese rats (fa/fa) of $407 \pm 12 \mathrm{~g}$ were purchased from Harlan (Interfauna Ibèrica, Barcelona, Spain). Rats and mice were made diabetic (Type 1) by a single intraperitoneal injection of a freshly prepared solution of streptozotocin $(70$ and $150 \mathrm{mg} / \mathrm{kg}$ body weight dissolved in $50 \mathrm{mmol} / \mathrm{l}$

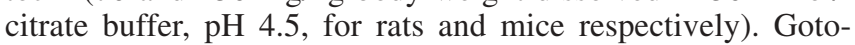
Kakizaki diabetic rats, a model of Type 2 diabetes, were purchased from M\&B Animal Models (Ry, Denmark). The animals were housed in animal quarters at $22^{\circ} \mathrm{C}$ with a 12 -h light and dark cycle, with free access to food and water.

Adipose tissue was ablated by removing the epididymal and perirenal adipose tissue under anaesthesia. A group of control animals was sham-operated. Blood was collected from the tail vein before the surgery, before the streptozotocin injection and 3 days after and plasma was prepared and stored at $-20^{\circ} \mathrm{C}$ until use.

All procedures used followed the principles of laboratory animal care and were approved by the Ethics Committee of the University of Barcelona.

Cell cultures. We cultured 3T3-L1 preadipocytes from the American Type Culture Collection (Manassas, Va., USA) in DMEM containing $25 \mathrm{mmol} / \mathrm{l}$ glucose and L-glutamine and supplemented with $10 \%$ (v/v) FCS. At 2 days after confluence (day 0), differentiation was induced with methylisobutylxanthine $(0.5 \mathrm{mmol} / \mathrm{l})$, dexamethasone $(0.25 \mu \mathrm{mol} / \mathrm{l})$ and insulin $(5 \mu \mathrm{g} / \mathrm{ml})$ in DMEM and $10 \%(\mathrm{v} / \mathrm{v})$ fetal bovine serum (FBS). After 2 days the methylisobutylxanthine and dexamethasone were removed and insulin was maintained for a further 2 days. From day 4 onwards, DMEM and 10\% (v/v) FBS were replaced every 2 days. Cells were used for experiments after 2 weeks of differentiation. To eliminate possible contamination by bovine SSAO, cell monolayers were washed several times in PBS and incubated in serum-free DMEM in the presence or absence of the indicated drugs. This was done $24 \mathrm{~h}$ or $48 \mathrm{~h}$ before collection of the medium. In the treatment with changes in the glucose concentration used, cells were washed in PBS 4 
days before collection of the medium, and cultured in low-glucose DMEM containing only $5 \mathrm{mmol} / \mathrm{l}$ glucose and $10 \%(\mathrm{v} / \mathrm{v})$ FBS. After 2 days cells were washed in PBS and maintained in serum-free low-glucose DMEM.

Cultured medium was collected and centrifuged at $200000 \mathrm{~g}$ for $2 \mathrm{~h}$ at $4^{\circ} \mathrm{C}$ to eliminate dead cells or contamination by membrane ghosts. After centrifugation the supernatant was concentrated using Centriprep and Centricon tubes (Millipore). The medium was maintained at $4^{\circ} \mathrm{C}$ during the protocol and stored at $-80^{\circ} \mathrm{C}$.

Human explants. Subcutaneous abdominal adipose tissue was obtained from patients undergoing dermolipectomy at the Department of Plastic Surgery of Toulouse Rangueil Hospital, France. The study was carried out with informed consent from subjects and in accordance with the Declaration of Helsinki as revised in 2000. Surgical samples were dissected from skin and vessels, rinsed once in warmed PBS and transferred to a sterile environment. The fat pads were cut into small pieces of 100 to $400 \mathrm{mg}$, distributed into $25-\mathrm{cm}^{2}$ polystyrene flasks (Falcon, Becton Dickinson, Meylan, France) containing from 5 to $6 \mathrm{~g}$ of adipose tissue, then placed in DMEM supplemented with $10 \%$ FCS, penicillin $(200 \mathrm{U} / \mathrm{ml})$, streptomycin $(50 \mu \mathrm{g} / \mathrm{ml})$ and gentamycin $(200 \mu \mathrm{g} / \mathrm{ml})$ and maintained at $37^{\circ} \mathrm{C}$ in a $7 \%$ $\mathrm{CO}_{2}$ chamber. One day later, the medium was changed to FCSfree DMEM and explants were treated with the indicated drugs or vehicle. After $48 \mathrm{~h}$ of treatment, the media were collected, ultra-centrifuged and concentrated as described above.

3T3-L1 adipocyte extracts. Cells were harvested and homogenised in an HES buffer (25 mmol/l HEPES, $2 \mathrm{mmol} / \mathrm{l}$ EDTA, $255 \mathrm{mmol} / \mathrm{l}$ sucrose) with antiproteases [1 $\mu \mathrm{mol} / \mathrm{l}$ pepstatin, $1 \mu \mathrm{mol} / 1$ leupeptin, 0.14 trypsin inhibitor units per $\mathrm{ml}$ aprotinin and $1 \mathrm{mmol} / \mathrm{l}$ phenylmethylsulfonylfluoride (PMSF)]. The lysates were then centrifuged at $2000 \mathrm{rpm}$ at $4{ }^{\circ} \mathrm{C}$ for 15 min to eliminate the fat cake, and supernatants were collected and stored at $-80^{\circ} \mathrm{C}$. Protein concentrations were measured by the Bradford method with $\gamma$-globulin as a standard.

Sialidase and $N$-glycosidase treatments. We incubated $100 \mu 1$ of concentrated culture medium or $20 \mu \mathrm{g}$ of adipocyte extract with Vibrio cholerae sialidase $\left(10 \mathrm{mU}, 2 \mathrm{~h}, 37^{\circ} \mathrm{C}\right)$, which removes $\alpha$ 2,3-, $\alpha$ 2,6- and $\alpha$ 2,8-linked sialic acids. Following the manufacturer's instructions, Peptide: N-glycosidase F (endoglycosidase F) treatment was used $\left(37^{\circ} \mathrm{C}\right.$ for $\left.2 \mathrm{~h}\right)$ to digest $\mathrm{N}$-linked oligosaccharides.

VAP-1/SSAO immunoprecipitation from mouse adipocyte lysates and plasma. Isolated mouse adipocytes were homogenised into homogenisation buffer containing $50 \mathrm{mmol} / \mathrm{l}$ HEPES, $\mathrm{pH} 7.4$, $150 \mathrm{mmol} / \mathrm{l} \mathrm{NaCl}, 10 \mathrm{mmol} / \mathrm{l}$ EDTA, $1 \mathrm{mmol} / \mathrm{l} \mathrm{PMSF}, 2 \mu \mathrm{mol} / \mathrm{l}$ pepstatin $\mathrm{A}$ and $2 \mu \mathrm{mol} / \mathrm{l}$ leupeptin. Fat-free homogenates were solubilised at $1 \mu \mathrm{g} / \mu \mathrm{l}$ in immunoprecipitation buffer (Tris $50 \mathrm{mmol} / \mathrm{l}, \mathrm{pH} 8,150 \mathrm{mmol} / \mathrm{l} \mathrm{NaCl}, 0.5 \%$ Triton $\mathrm{X}-100,0.5 \%$ sodium deoxycholate, $0.1 \% \mathrm{SDS}$ ), in the presence of protease inhibitors $(1 \mu \mathrm{g} / \mathrm{ml}$ pepstatin and leupeptin, $1 \mathrm{U} / \mathrm{ml}$ aprotinin and $1 \mathrm{mmol} / \mathrm{l} \mathrm{PMSF}$ ). This was done for $1 \mathrm{~h}$ at $4^{\circ} \mathrm{C}$. Insoluble material was removed by centrifugation $(13000 \mathrm{~g})$ for $10 \mathrm{~min}$ at $4^{\circ} \mathrm{C}$. Mouse adipocyte lysates $(50 \mu \mathrm{g})$ or plasma from control and diabetic mice $(700 \mu \mathrm{l})$ were incubated overnight at $4^{\circ} \mathrm{C}$ with an anti-VAP-1 antibody (TK7-88) previously coupled to protein GSepharose 4B. For negative control, lysates or plasma were incubated with protein G-Sepharose $4 \mathrm{~B}$ in the absence of antibody anti-VAP-1. The immunocomplexes were washed three times in homogenisation buffer with $0.1 \%$ Tween, and tested for SSAO activity, or boiled in Laemmli sample buffer containing $0.1 \mathrm{~mol} / \mathrm{l}$ dithiothreitol (DTT), and subjected to SDS-PAGE.
Electrophoresis and immunoblot analysis. SDS-polyacrylamide gel electrophoresis was done on $5 \mu \mathrm{g}$ of membrane proteins or $20 \mu \mathrm{l}$ of concentrated medium following Laemmli [19] in reducing conditions when specified. Proteins were transferred to Immobilon in buffer consisting of $20 \%$ methanol, $200 \mathrm{mmol} / \mathrm{l}$ glycine and $25 \mathrm{mmol} / \mathrm{l} \mathrm{Tris,} \mathrm{pH} \mathrm{8.3.} \mathrm{After} \mathrm{transfer,}$ the membranes were blocked with $10 \%$ non-fat milk in phosphate-buffered saline for $1 \mathrm{~h}$ at $37^{\circ} \mathrm{C}$, and then incubated with antibodies raised against SSAO, GLUT-4 or caveolin-1. The polyclonal anti-SSAO antibody was used to detect by immunoblot the VAP-1/SSAO protein immunoprecipitated with the monoclonal antibody TK 7-88. Transfer was confirmed by Coomassie Blue staining of the gel after electroblot. The immune complex was detected using the ECL western blot detection system. Immunoblots were done in conditions in which autoradiographic detection was in the linear response range.

Measurement of SSAO activity. Amine oxidase activity was measured radiochemically as described previously [40]. The reaction was performed in $200 \mu \mathrm{l}$ of $0.2 \mathrm{~mol} / \mathrm{l}$ phosphate buffer at $37^{\circ} \mathrm{C}$ in the presence of benzylamine $(25 \mu \mathrm{mol} / \mathrm{l})$ or at the indicated concentrations (15 kBq/assay) at $\mathrm{pH} 7.4$ for $60 \mathrm{~min}$. Blank values were measured in assays pre-incubated for $15 \mathrm{~min}$ with $1 \mathrm{mmol} / \mathrm{l}$ semicarbazide to totally inhibit SSAO activity. Reactions were stopped by adding $50 \mu \mathrm{l}$ of $4 \mathrm{~N} \mathrm{HCl}$, and the reaction products were extracted with toluene/ethyl acetate $1: 1(\mathrm{v} / \mathrm{v})$ before liquid scintillation counting. The kinetic parameters were calculated using the non-linear regression analysis of Graph-Pad Prism (GraphPad, San Diego, Calif., USA). The SSAO activity present in the medium was expressed as $\mathrm{pmol} \cdot \mathrm{h}^{-1}$. plate $^{-1}$, one plate representing $2.5 \pm 0.3 \mathrm{mg}$ of protein and around $3 \times 10^{6}$ cells.

Statistics. Results are given as means \pm SEM. Student's $t$ test was used to compare two groups. When experimental series involved more than two groups, statistical analysis was done by ANOVA and further Dunnett $t$ tests using the program GraphPad Prism. A $p$ value of less than 0.05 was considered to be statistically significant.

\section{Results}

Diabetes and obesity increase the amount of plasma $V A P-1 / S S A O$. Streptozotocin-induced diabetic rats, a model of Type 1 diabetes, had increased SSAO activity in the plasma. We also found that Type 1 diabetic mice had higher plasma SSAO activity (Fig. 1b). Use of an anti-mouse VAP-1 antibody TK7-88 able to immunoprecipitate the mouse adipocyte VAP-1 protein (Fig. 1c) showed a higher SSAO activity in the immunoprecipitate from diabetic mouse plasma than from that of controls (Fig. 1b). Under these conditions, the antibody TK7 -88 immunoprecipitated $79 \pm 7 \%$ of total plasma SSAO activity. We also found increased SSAO activity in the plasma of Type 2 diabetic Goto-Kakizaki rats (Fig. 1a).

To assess whether obesity and/or insulin resistance alter SSAO activity in the absence of diabetes, we compared plasma SSAO activity in 3-month-old genetically obese Zucker rats (fa/fa) with that of lean controls (Fa/?). Obese Zucker rats have peripheral insulin resistance but not diabetes, and plasma glucose 


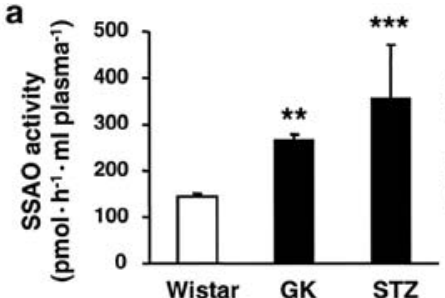

b

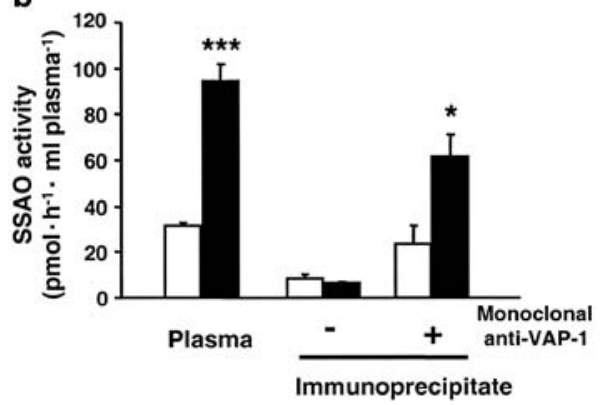

Fig. 1a-c. Plasma SSAO activity is regulated by modification of adipose tissue metabolism. Plasma SSAO activity is enhanced (a) in Type 1 and Type 2 diabetes and obesity in rats. Values are means \pm SEM of three to ten independent observations per group. In Type 1 diabetes in mice (b) plasma SSAO activity is enhanced and associated with VAP-1 protein. The average plasma glucose concentration was $8.0 \pm 0.3 \mathrm{mmol} / \mathrm{l}$ in the control group (white columns, animals injected with vehicle) and $32 \pm 0.7 \mathrm{mmol} / \mathrm{l}$ in the diabetic group (black columns). Plasma from control and diabetic animals was immunoprecipitated with monoclonal anti-VAP-1 antibody (TK7-88). SSAO activity was measured in crude plasma and immunoprecipitated plasma. Non-

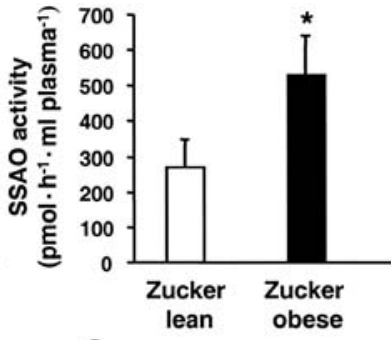

C

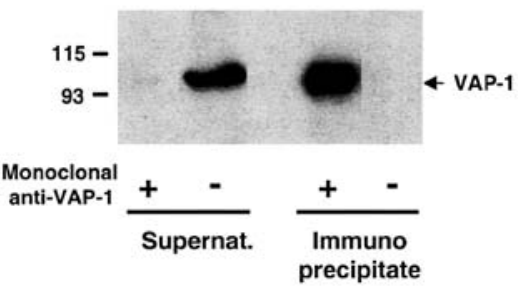

specific immunoprecipitation was measured in the absence of antibody. Results are means of 4 to 5 experiments. *, ** and $* * *$ stand for significant differences at $p<0.05, p<0.02$ and $p<0.01$ respectively. Mouse adipocyte lysates $(50 \mu \mathrm{g})$ were incubated overnight at $4^{\circ} \mathrm{C}$ (c) with an anti-VAP-1 antibody (TK7-88) previously coupled to protein G-Sepharose 4B. For negative control, lysates were incubated with protein $\mathrm{G}$-Sepharose $4 \mathrm{~B}$ without the antibody. The immunocomplexes were subjected to SDS-PAGE. The autoradiogram is representative of three independent experiments. SSAO, semicarbazide-sensitive amine oxidase; GK, Goto-Kakizaki diabetic rats; STZ, streptozotocin-induced diabetic animals; VAP-1, vascular adhesion protein-1
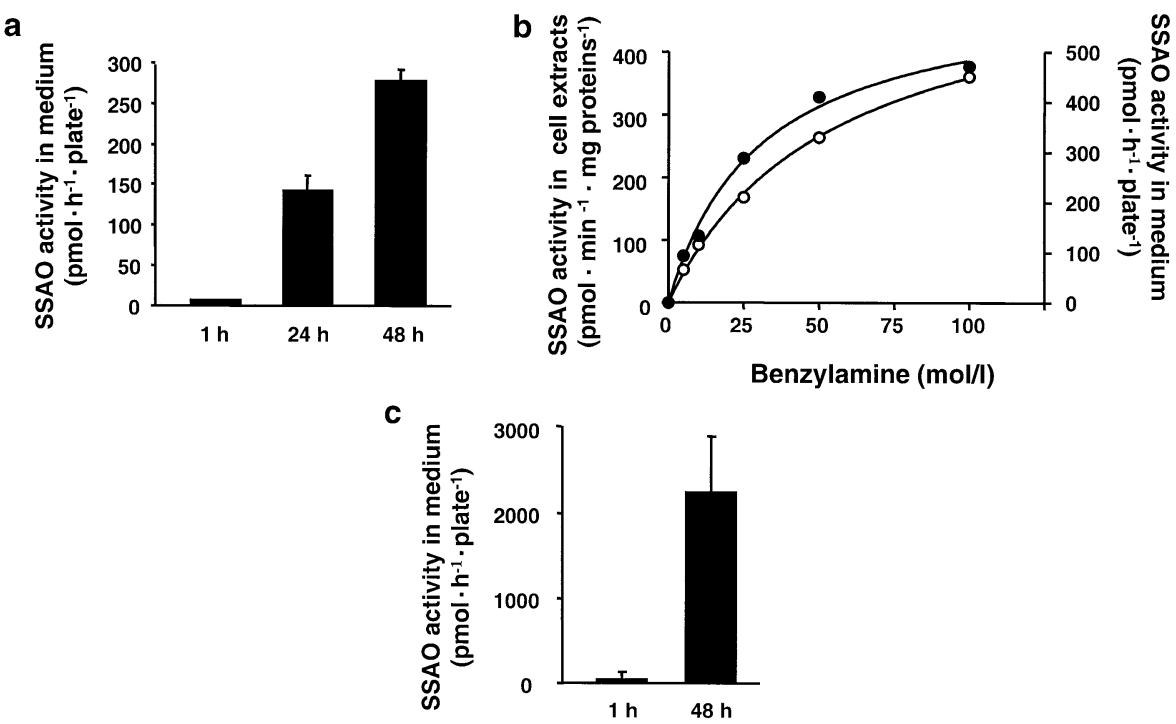

Fig. 2a-c. Human adipose tissue and 3T3-L1 adipocytes release SSAO activity into the culture medium. 3T3-L1 adipocytes were incubated (a) in bovine serum-free medium for $1 \mathrm{~h}, 24 \mathrm{~h}$ or $48 \mathrm{~h}$ and the medium was then concentrated. SSAO activity was measured by incubating $20 \mu \mathrm{l}$ of medium with $25 \mu \mathrm{mol} / \mathrm{l}$ of radiolabelled benzylamine for $1 \mathrm{~h}$ at $37^{\circ} \mathrm{C}$, followed by extraction of the reaction products and counting. Values are means \pm SEM of three independent observations per group, each analysis being processed in duplicate. Kinetic of SSAO activity released into the 3T3-L1 medium, compared with cell extract activity (b). The Michaelis-Menten constant $\mathrm{K}_{\mathrm{m}}$ of 3T3-L1 membrane and medium

SSAO activity was determined by incubating 3T3-L1 extracts (5 $\mu \mathrm{g}$ of proteins) (closed circles, left Y-axis) or concentrated 3T3L1 serum-free medium $(20 \mu \mathrm{l})$ (open circles, right Y-axis) with radiolabelled benzylamine from 5 to $100 \mu \mathrm{mol} / \mathrm{l}$ (see text for means \pm SEM values). A representative graph from three independent experiments is shown. Human adipose tissue explants (c) were cultured and incubated for $1 \mathrm{~h}$ or $48 \mathrm{~h}$ in FCS-free medium. At the end of incubation, the medium was collected, and SSAO activity determined as described above. Values are means \pm SEM of three independent observations, each analysis being processed in duplicate. SSAO, semicarbazide-sensitive amine oxidase 
a
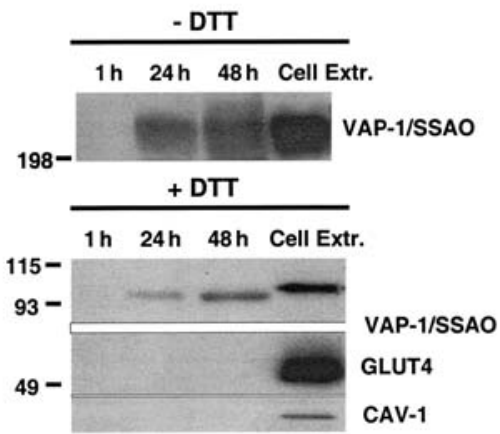

C

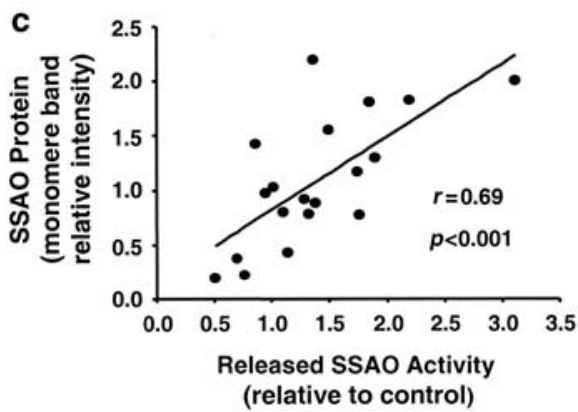

Fig. 3a-d. Soluble SSAO and the integral membrane proteins have a dimeric structure and present similar levels of N-glycosylation and sialidation. 3T3-L1 adipocytes (a) were incubated in bovine serum-free medium for $1 \mathrm{~h}, 24 \mathrm{~h}$ or $48 \mathrm{~h}$, and the corresponding medium and 3T3-L1 cells processed as described (Materials and methods). Amounts of VAP-1/SSAO in the 3T3-L1 medium $(20 \mu \mathrm{l})(1 \mathrm{~h}, 24 \mathrm{~h}, 48 \mathrm{~h})$ and in the cell extract ( $5 \mu \mathrm{g}$ of proteins) were assayed by western blot in non-reducing (-DTT $2 \mathrm{mmol} / \mathrm{l}$ ) and reducing (+DTT $2 \mathrm{mmol} / \mathrm{l})$ conditions. GLUT4 and caveolin-1 proteins were used to detect contamination of the medium by cell ghosts. Positions of standard molecular weight are indicated. Autoradiogram representative of three independent experiments. Immunoprecipitation (b) of SSAO activity from 3T3-L1 medium by an anti-VAP-1 antibody. 3T3-L1 medium was immunoprecipitated with monoclonal anti-VAP-1 antibody (TK7-88). SSAO activity was measured in corresponding supernatants and immunoprecipitated. Non-specific immunoprecipitation was measured in the absence of antibody. Results are means of four to five experiments. Insert: autoradiogram of immunoprecipitates representative of three independent experiments. Correlation (c) between VAP-1 protein concentrations and SSAO activity in 3T3-L1 medium. Data from different experiments are represented. Control values correspond to untreated media. Values of treated media were referred to the corresponding control. $r=0.69, p<0.001$. Medium and cell extracts (d) after $48 \mathrm{~h}$ of culture were digested with sialidase or endoglycosidase F (see Materials and methods) to eliminate sialic acid residues and/or $\mathrm{N}$-glycosylation. For each treatment, the electrophoretic mobility of VAP-1/SSAO protein was assayed by western blot. Autoradiogram representative of three independent experiments. SSAO, semicarbazide-sensitive amine oxidase; VAP-1, vascular adhesion protein-1; DTT, dithiothreitol; CAV-1, caveolin-1; endoF, endoglycosidase $\mathrm{F}$

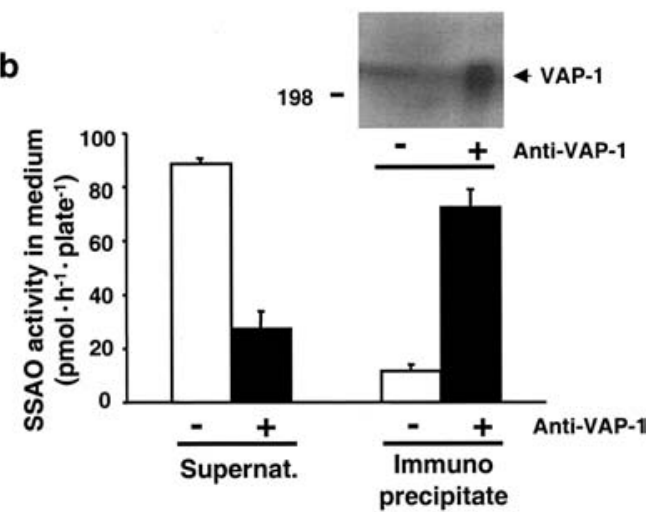

d

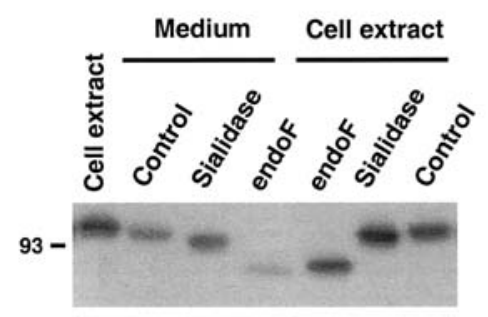

concentrations between both groups were not different $(8.5 \pm 0.5$ and $7.8 \pm 0.4 \mathrm{mmol} / \mathrm{l}$ for the obese and the lean animals respectively).

3T3-L1 adipocytes and human explants of adipose tissue released SSAO activity into the medium. SSAO activity was detected in the medium, increasing in a time-dependent manner (Fig. 2a). After $1 \mathrm{~h}$ in contact with differentiated adipocytes the medium showed no significant SSAO activity. After $24 \mathrm{~h}$, SSAO activity was detected $\left(141 \pm 19 \mathrm{pmol} \cdot \mathrm{h}^{-1} \cdot \mathrm{plate}^{-1}\right)$, which doubled in 2 days $\left(278 \pm 13 \mathrm{pmol} \cdot \mathrm{h}^{-1} \cdot\right.$ plate $\left.^{-1}\right)$. No changes were observed in the membrane semicarbazide-sensitive benzylamine oxidation at $24 \mathrm{~h}$ and $48 \mathrm{~h}$ (data not shown). The $\mathrm{K}_{\mathrm{m}}$ values of benzylamine oxidation catalysed by the medium and the membrane preparations $(43 \pm 8 \mu \mathrm{mol} / \mathrm{l}$ and $25 \pm 5 \mu \mathrm{mol} / \mathrm{l}$ respectively) (Fig. 2b) indicate that both activities are closely related.

With regard to the human adipocytes studied, we found that after $48 \mathrm{~h}$ the medium of the relevant human explants also showed increased SSAO activity (Fig. 2c).

3T3-L1 adipocytes produce a soluble VAP-1/SSAO protein distinct from the integral membrane form. In parallel to the time-dependent enhancement of soluble SSAO activity the amount of VAP-1/SSAO protein present in the medium also increased (Fig. 3a). SSAO was hardly detected at $1 \mathrm{~h}$. After $48 \mathrm{~h}$ incubation the amount of protein increased by $220 \%(n=4)$ versus the $24-h$ value. Like the membrane form, the soluble protein was dimeric in non-reducing conditions, but monomeric after dithiothreitol treatment (Fig. 3a). Undifferentiated adipocytes, which do not express surface 
a

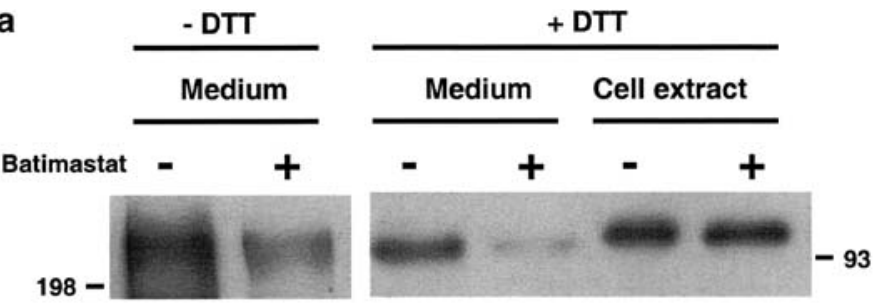

b

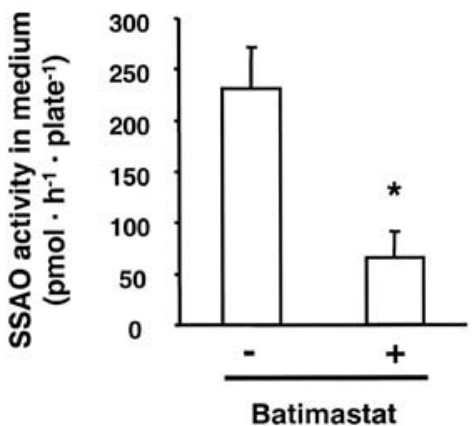

Fig. 4a-c. The release of SSAO by adipocytes is a process dependent on metalloprotease. 3T3-L1 adipocytes were incubated (a) for $48 \mathrm{~h}$ with or without $5 \mu \mathrm{mol} / \mathrm{l}$ batimastat and the medium and 3T3-L1 cells were processed (see Materials and methods). Amounts of VAP-1/SSAO in 3T3-L1 medium $(20 \mu \mathrm{l})$ and in cell extract preparation $(5 \mu \mathrm{g}$ of proteins) were assayed by western blot in non-reducing and reducing conditions. Autoradiogram representative of three independent experiments. SSAO activity in control and batimastat-treated media from 3T3-L1 (b) and human adipose tissue explants (c). Values are means \pm SEM of three independent experiments done in duplicate. ${ }^{*} p<0.05$; SSAO, semicarbazide-sensitive amine oxidase; DTT, dithiothreitol

integral SSAO, did not release any detectable SSAO enzymatic activity or SSAO protein (data not shown).

A possible contamination of the collected and concentrated media by SSAO-containing adipocyte cell membranes was ruled out because (i) neither GLUT4 nor caveolin-1 was detected in the medium, while both were detected in 3T3-L1 extracts (Fig. 3a), and (ii), as observed in reducing conditions, the SSAO in the medium was approximately $2 \mathrm{M}_{\mathrm{r}}$ smaller than that in adipocytes (Fig. 3a).

We also assessed whether SSAO activity and VAP1 protein were associated in the 3T3-L1 culture medium. Immunoprecipitation of VAP-1 from the 3T3-L1 culture medium showed that, in these conditions, more than $70 \%$ of the SSAO activity was also present in the immunoprecipitates (Fig. 3b). In addition, we found a strong correlation $(r=0.7, p<0.001)$ between the amount of VAP-1 and the SSAO activity detected in 19 3T3-L1 culture media obtained from separate experiments (Fig. 3c). c

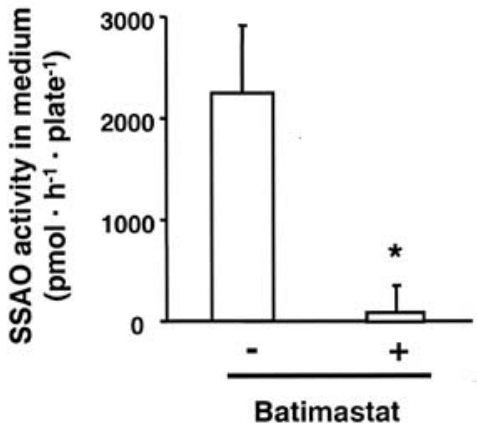

Soluble SSAO and the integral membrane protein present similar amounts of $N$-glycosylation and sialidation. SSAO secreted by 3T3-L1 adipocytes was also $\mathrm{N}$-glycosylated and sialidated (Fig. 3c). The treatments with endoglycosidase $\mathrm{F}$ or with sialidase caused an identical change in mobility of membrane and soluble SSAO protein (Fig. 3c) (corresponding to changes of 3 and $15 \mathrm{M}_{\mathrm{r}}$ after endoglycosidase $\mathrm{F}$ and sialidase treatment respectively).

The release of SSAO by adipocytes is dependent on metalloprotease activity. Next, we examined whether the release of SSAO by adipocytes resulted from a proteolytic process, and found that the differences in apparent molecular weights (Fig. 3) between the soluble and the membrane form are consistent with the relevant cleavage site. We also studied the effect of a matrix metalloprotease inhibitor on secreted SSAO levels. While adipocyte membrane SSAO concentrations were unaffected by the treatment, the presence of batimastat decreased the release of SSAO protein to $20 \pm 1 \%$ of control (Fig. 4a). Activity in the medium was also reduced to $20 \%$ of control (Fig. 4b). The release of SSAO activity by human adipose explants was completely inhibited by batimastat (Fig. 4c).

The release of SSAO by adipocytes is enhanced by $T N F-\alpha$. To further study the possible regulation of soluble SSAO release by factors implicated in adipose tissue physiopathology and diabetes, 3T3-L1 adipocytes were incubated in the presence or absence of different hormones or metabolites for $48 \mathrm{~h}$.

Usually, 3T3-L1 adipocytes are cultured in a glucose-rich medium ( $25 \mathrm{mmol} / \mathrm{l}$ glucose). For our purpose, they were incubated for 4 days in a medium 
a
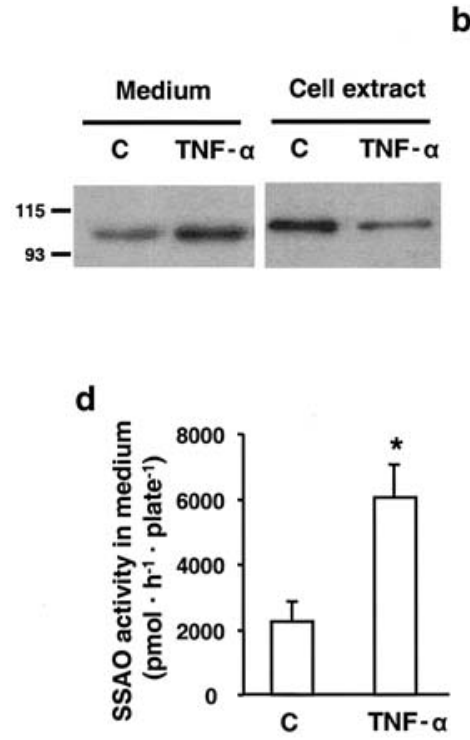

Fig. 5a-f. Regulation of VAP-1/SSAO release by 3T3-L1 adipocytes and human tissue explants. 3T3-L1 adipocytes (a) were incubated in bovine serum-free medium for $48 \mathrm{~h}$ with or without $5 \mathrm{nmol} / \mathrm{l} \mathrm{TNF}-\alpha$. Amounts of VAP-1/SSAO in 3T3-L1 medium $(20 \mu \mathrm{l}$; left panel $)$ and in cell extract preparation $(5 \mu \mathrm{g}$ of proteins; right panel) were assayed by immunoblot under reducing conditions. Autoradiograms are representative of four to six independent experiments. VAP-1/SSAO protein concentrations (b) in medium were quantified by densitometry of the autoradiograms (histogram). Values, relative to control, are means \pm SEM of four to six independent experiments $(* p<0.05)$. SSAO activity was determined in control and TNF$\alpha$-treated media (c) (method: see legend, Fig. 2). Values, expressed as pmol of oxidised benzylamine per $\mathrm{h}$ per plate, are means \pm SEM of four to six independent experiments performed in duplicate $(* * p<0.02)$. Human subcutaneous adipose tissue explants were treated or not (d) with $5 \mathrm{nmol} / \mathrm{l}$ human TNF- $\alpha$. After treatments, the SSAO activity of the concentrated media was measured as described for Fig. 2. Values are means \pm SEM of three experiments done in duplicate $\left({ }^{*} p<0.05\right)$. 3T3-L1 adipocytes were treated (e) with $1 \mathrm{nmol} / \mathrm{l}$ insulin or $50 \mu \mathrm{mol} / \mathrm{l}$ benzylamine in the absence or presence of $1 \mathrm{nmol} / 1 \mathrm{TNF}-\alpha$. Values are means \pm SEM of three experiments done in triplicate. $* *$, results significantly different from the condition in absence of TNF- $\alpha$ at $p<0.05$; SSAO, semicarbazide-sensitive amine oxidase; VAP-1, vascular adhesion protein-1; C, control; Ins, insulin; Benz, benzylamine

containing only $5 \mathrm{mmol} / \mathrm{l}$ glucose. The release of SSAO was not affected (data not shown).

Because we observed an enhancement of plasma SSAO in obese rats, 3T3-L1 were incubated for $48 \mathrm{~h}$ in the presence of 5 and $50 \mathrm{ng} / \mathrm{ml}$ of leptin. The cytokine did not modify the release of VAP-1/SSAO (data not shown).

The cytokine TNF- $\alpha$ decreased the SSAO content in the adipocyte extracts (Fig. 5a) but an increased VAP-1/SSAO protein amount and enzymatic activity were found in the incubation medium (Fig. 5b, c). As in control conditions (Fig. 4), the shedding of VAP-
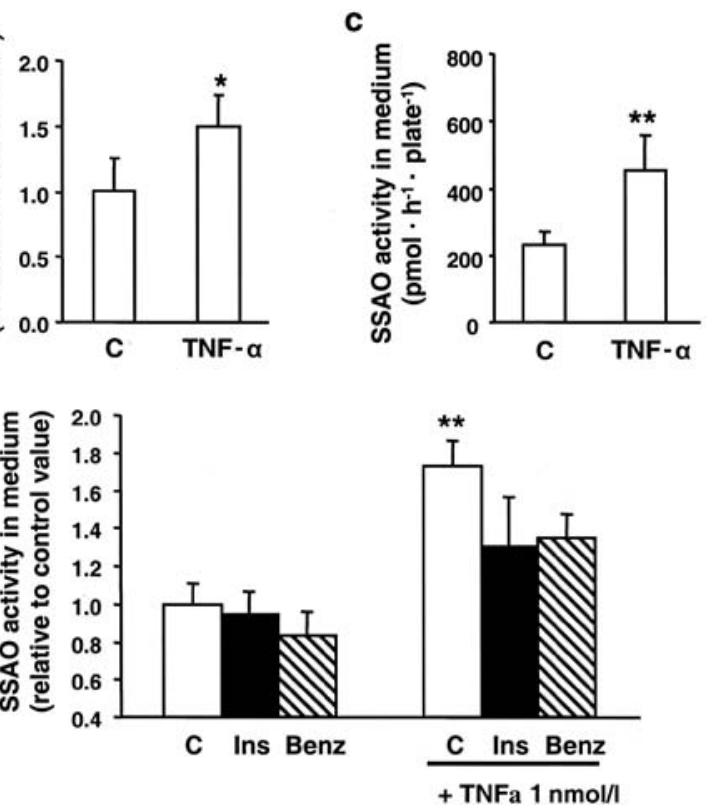

1/SSAO induced by TNF- $\alpha$ was dependent on matrix metalloprotease activity: $63 \%$ of the SSAO release was inhibited by batimastat.

As with 3T3-L1 cells, TNF- $\alpha$ caused a threefold stimulation in the release of SSAO by human explants (Fig. 5d).

Insulin at concentrations of 1 or $100 \mathrm{nmol} / \mathrm{l}$ did not modify the release of VAP-1/SSAO (Fig. 5e and data not shown), but partially counteracted the stimulatory effect of $1 \mathrm{nmol} / \mathrm{l} \mathrm{TNF}-\alpha$ (Fig. 5e).

We also tested whether the production of hydrogen peroxide by SSAO could have an influence on the release of VAP-1/SSAO. 3T3-L1 cells treated with benzylamine $(50 \mu \mathrm{mol} / \mathrm{l})$, alone or in combination with TNF- $\alpha$, showed no effect of benzylamine by itself, though it did partially inhibit the TNF- $\alpha$-induced release of VAP-1/SSAO (Fig. 5e).

The release of SSAO by adipocytes is regulated by semicarbazide, an inhibitor of SSAO activity. Our study of the influence of the enzyme activity on SSAO shedding found that, in 3T3-L1 cells treated with the inhibitor semicarbazide, this inhibitor completely inhibited amine oxidase activity in the medium and in the corresponding cell extract after $48 \mathrm{~h}$ of treatment (data not shown). The protein amount was unchanged in the cell extracts (data not shown), but increased in the medium (Fig. 6).

Partial ablation of rat internal adipose tissue reduces the amount of plasma SSAO activity. Our examination of the impact of adipose tissue on plasma VAP-1/SSAO in living Wistar rats showed that in the ablated rat group SSAO activity decreased to $85 \%$ and was significantly different from the sham-operated group $(p=0.037)$ (Fig. 7). The differences between ablated and non-ablated animals became larger three days after the streptozotocin injection (Fig. 7). 

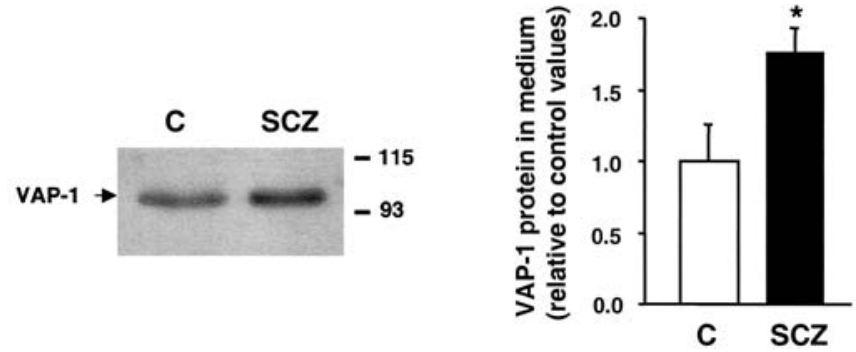

Fig. 6. Regulation of SSAO release by 3T3-L1 adipocytes in the presence of semicarbazide. 3T3-L1 adipocytes were incubated in bovine serum-free medium for $48 \mathrm{~h}$ with or without semicarbazide. Medium VAP-1/SSAO was assayed by western blot in reducing conditions (autoradiogram) and quantified by densitometry. Autoradiograms are representative of three to nine separate experiments. *, significant at $p<0.05$; SSAO, semicarbazide-sensitive amine oxidase; VAP-1, vascular adhesion protein-1; C, control; SCZ, semicarbazide

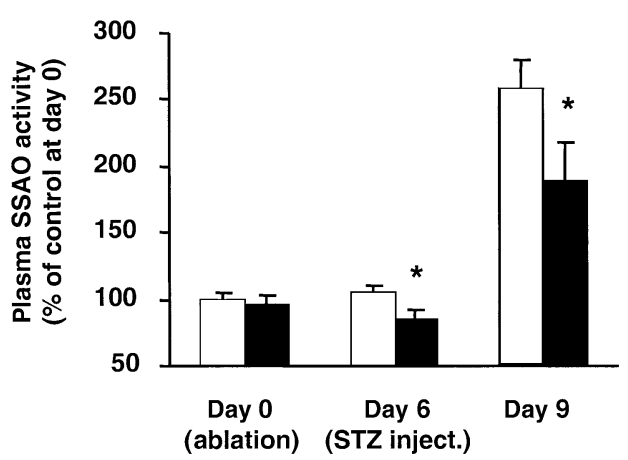

Fig. 7. Partial ablation of internal white adipose tissue reduces plasma SSAO activity. Epididymal and perirenal white adipose tissue from Wistar rats was surgically removed (black bars) or not (sham-operated animals, open bars). Blood extraction and plasma preparations were processed before surgery (day 0), before the injection of streptozotocin (day 6) and 3 days after the streptozotocin injection (day 9). SSAO activity was measured as described (legend Fig. 2). Values $(n=6-12)$ are expressed as percentage of the activity of the control group determined before ablation $(100 \%)$. $* p<0.05$. SSAO, semicarbazide-sensitive amine oxidase; STZ, streptozotocin

\section{Discussion}

The present study describes (i) the increased plasma VAP-1/SSAO in three animal models of diabetes or obesity, (ii) the release of VAP-1/SSAO by 3T3-L1 adipocytes and human adipose tissue explants by a process dependent on matrix metalloprotease, (iii) the stimulation of this release by TNF- $\alpha$, whose effect is counteracted by insulin and benzylamine, and finally (iv) the in vivo regulation of VAP-1/SSAO concentrations in parallel with modifications of adipose tissue mass.

Recently a correlation was found between adiposity, insulin resistance and the presence of soluble adhesion molecules in Type 2 diabetes [12]. In keeping with these observations, we found that plasma SSAO activity was increased in Type 1 diabetic rats, as previously reported [12], but also in Type 1 diabetic mice and in Type 2 diabetic rats. The increments of SSAO activity associated with animal models of Type 1 and Type 2 diabetes are of a similar size to the increase of VAP-1 protein and SSAO activity previously reported in human diabetes $[31,32,33]$. If VAP-1/SSAO derives from adipose tissue, we can expect its plasma levels to increase in obesity or in insulin resistance. In fact, a previous study showed a positive correlation between BMI and plasma SSAO activity in diabetic patients [27]. More recently, increased SSAO activity was found in the plasma of morbidly obese, non-diabetic subjects, compared with non-obese subjects [28]. In agreement with these previous data, we found that soluble SSAO activity was higher in 3-month-old non-diabetic Zucker obese rats than in lean controls. Moreover, the reduction in plasma SSAO in rats ablated under non-diabetic and diabetic conditions supports the view that adipose tissue is a source of plasma SSAO in both conditions.

Human, rat or murine plasma SSAO activity and VAP-1 concentrations are too low to directly detect the associated plasma protein by western blot. However, previous reports support the idea that soluble VAP1 protein and soluble SSAO activity are identical, in as far as (i) the elimination of VAP-1 from human plasma by immunoaffinity is accompanied by a suppression of SSAO activity [34], and (ii) there is a correlation between the amount of VAP-1 protein determined by ELISA and the SSAO activity in serum from diabetic patients [32]. Taken together, our results from VAP-1 immunoprecipitation, the correlation found by us between VAP-1 protein and SSAO activity, and the above-mentioned, previously reported data strongly argue that (i) soluble VAP-1 protein and plasma SSAO activity are identical, and (ii) the presence of higher VAP-1 protein levels is associated with increased SSAO activity in diabetic rodents and humans.

Depending on the adhesion protein, the corresponding soluble form can be released into the circulation via different mechanisms: shedding from the membrane-bound form, or alternatively splicing of the gene encoding the integral protein. Our data suggest that this release is by shedding, because: (i) the difference in electrophoretic mobility between the soluble form and the membrane form of 3T3-L1 VAP-1/SSAO corresponds to approximately $2 \mathrm{M}_{\mathrm{r}}$, which is consistent with loss of the transmembrane domain [24]; (ii) the soluble and membrane-bound proteins show similar levels of glycosylation and sialidation; and (iii) the metalloprotease inhibitor batimastat almost abolished release of SSAO by 3T3-L1 and by human adipose tissue.

We also observed that TNF- $\alpha$ clearly enhanced the release of VAP-1/SSAO by 3T3-L1 adipocytes and human adipose tissue. In cultured cells other than 3T3- 
L1, TNF- $\alpha$ can also induce the release of soluble adhesion molecules $[41,42]$. We did not observe any direct influence of glucose itself or leptin on VAP-1/SSAO release. However, in this connection, it was recently reported that plasma glucose concentrations do not modulate plasmatic VAP-1/SSAO concentrations in humans [32]. Thus the increased serum VAP-1/SSAO in diabetes or obesity could, at least in part, be a consequence of insulin resistance promoted by TNF- $\alpha$, whose action on the shedding of adipose tissue VAP1/SSAO can be modulated by insulin. In Type 1 diabetes the absence of insulin could favour the release of VAP-1/SSAO.

Besides its well-known energetic functions, several discoveries have implicated the adipose tissue in regulatory functions through the secretion of endocrine or paracrine factors [35]. It has recently been shown that weight loss results in a reduction of soluble adhesion molecules in obese subjects [43]. It is conceivable that adipose tissue could be a source of adhesion molecules other than VAP-1/SSAO. As a source of soluble adhesion molecules enhanced in diabetes and obesity, the adipose tissue could contribute to the cardiovascular complications associated with these conditions. Through its capacity to enhance circulating lymphocyte binding to endothelial cells [4], increased circulating SSAO could participate in the development of the cardiovascular complications, e.g. angiopathy, retinopathy, which are common in diabetes. Possible effects of soluble VAP-1/SSAO on the vasculature include a contribution to angiogenesis. Indeed, the physiology of VAP-1/SSAO has some similarities with secreted acidic cysteine-rich protein (SPARC), another matrix protein which is also shed by matrix metalloprotease [44] and whose release by adipose tissue is increased in obesity [45]. As angiogenesis can be promoted by SPARC [44] or by other adhesion proteins such as E-selectin and VCAM-1 [17], the angiogenic capacities of circulating VAP-1/SSAO are of great interest, as is the possible autocrine effect of soluble VAP-1/SSAO on adipocytes. In conclusion, our studies and those referred to above strongly suggest that soluble VAP-1/SSAO plays a physiological role, providing, in the case of the present study, a link between adipose tissue, inflammation, diabetes, obesity, and cardiovascular complications.

Acknowledgements. This study was supported by research grants from the Dirección General de Investigación Científica y Técnica, Spain (PM98/0197), the Spanish Ministry of Science and Technology (SAF 2002-02125), by grant 1999SGR 00039 from Generalitat de Catalunya, Spain, by a grant from Fondo de Investigaciones Sanitarias (00/0125), and by grants from the European Commission (Quality of Life, QLG-CT1999-00295), COST B17 Action and Fundació Marató de TV3 (300720), and the Carlos III Health Institute (RCMN CO3/08, RGDM G03/212 and RGTO G03/028). A. Abella is recipient of a pre-doctoral fellowship from the Universitat de Barcelona. S. Garcia-Vicente has a pre-doctoral fellowship from the Carlos III Health Institute. We thank J. Chillarón, L. Dejean and
M. Grasa for helpful discussions, the staff of the animal facility of the Barcelona Science Park, and R. Rycroft for his editorial support.

\section{References}

1. Butcher EC, Picker LJ (1996) Lymphocyte homing and homeostasis. Science 272:60-66

2. Springer TA (1994) Traffic signals for lymphocyte recirculation and leukocyte emigration: the multistep paradigm. Cell 76:301-314

3. Gearing AJ, Newman W (1993) Circulating adhesion molecules in disease. Immunol Today 14:506-512

4. Kurkijarvi R, Adams DH, Leino R, Mottonen T, Jalkanen S, Salmi M (1998) Circulating form of human vascular adhesion protein-1 (VAP-1): increased serum levels in inflammatory liver diseases. J Immunol 161:1549-1557

5. Rothlein R, Mainolfi EA, Czajkowski M, Marlin SD (1991) A form of circulating ICAM-1 in human serum. J Immunol 147:3788-3793

6. Blann AD, Tse W, Maxwell SJ, Waite MA (1994) Increased levels of the soluble adhesion molecule E-selectin in essential hypertension. J Hypertens 12:925-928

7. Gearing AJ, Hemingway I, Pigott R, Hughes J, Rees AJ, Cashman SJ (1992) Soluble forms of vascular adhesion molecules, E-selectin, ICAM-1, and VCAM-1: pathological significance. Ann NY Acad Sci 667:324-331

8. Lampeter ER, Kishimoto TK, Rothlein R et al. (1992) Elevated levels of circulating adhesion molecules in IDDM patients and in subjects at risk for IDDM. Diabetes 41: 1668-1671

9. Olson JA, Whitelaw CM, McHardy KC, Pearson DW, Forrester JV (1997) Soluble leucocyte adhesion molecules in diabetic retinopathy stimulate retinal capillary endothelial cell migration. Diabetologia 40:1166-1171

10. Roep BO, Heidenthal E, de Vries RR, Kolb H, Martin S (1994) Soluble forms of intercellular adhesion molecule-1 in insulin-dependent diabetes mellitus. Lancet 343:15901593

11. Bluher M, Unger R, Rassoul F, Richter V, Paschke R (2002) Relation between glycaemic control, hyperinsulinaemia and plasma concentrations of soluble adhesion molecules in patients with impaired glucose tolerance or Type II diabetes. Diabetologia 45:210-216

12. Leinonen E, Hurt-Camejo E, Wiklund O, Hulten LM, Hiukka A, Taskinen MR (2003) Insulin resistance and adiposity correlate with acute-phase reaction and soluble cell adhesion molecules in type 2 diabetes. Atherosclerosis 166:387-394

13. Marfella R, Esposito K, Giunta R et al. (2000) Circulating adhesion molecules in humans: role of hyperglycemia and hyperinsulinemia. Circulation 101:2247-2251

14. Hackman A, Abe Y, Insull W Jr et al. (1996) Levels of soluble cell adhesion molecules in patients with dyslipidemia. Circulation 93:1334-1338

15. Blann AD, Lip GY (2000) Cell adhesion molecules in cardiovascular disease and its risk factors-what can soluble levels tell us? J Clin Endocrinol Metab 85:1745-1747

16. Ridker PM, Hennekens CH, Roitman-Johnson B, Stampfer MJ, Allen J (1998) Plasma concentration of soluble intercellular adhesion molecule 1 and risks of future myocardial infarction in apparently healthy men. Lancet 351:88-92

17. Koch AE, Halloran MM, Haskell CJ, Shah MR, Polverini PJ (1995) Angiogenesis mediated by soluble forms of E-selectin and vascular cell adhesion molecule-1. Nature 376: $517-519$ 
18. Andres N, Lizcano JM, Rodriguez MJ, Romera M, Unzeta M, Mahy N (2001) Tissue activity and cellular localization of human semicarbazide-sensitive amine oxidase. J Histochem Cytochem 49:209-217

19. Hwang ST (2001) Mechanisms of T-cell homing to skin. Adv Dermatol 17:211-241

20. Atkinson MA, Eisenbarth GS (2001) Type 1 diabetes: new perspectives on disease pathogenesis and treatment. Lancet 358:221-229

21. Glass CK, Witztum JL (2001) Atherosclerosis. The road ahead. Cell 104:503-516

22. Salmi M, Jalkanen S (1992) A 90-kilodalton endothelial cell molecule mediating lymphocyte binding in humans. Science 257:1407-1409

23. Bono P, Salmi M, Smith DJ, Jalkanen S (1998) Cloning and characterization of mouse vascular adhesion protein-1 reveals a novel molecule with enzymatic activity. J Immunol 160:5563-5571

24. Smith DJ, Salmi M, Bono P, Hellman J, Leu T, Jalkanen S (1998) Cloning of vascular adhesion protein 1 reveals a novel multifunctional adhesion molecule. J Exp Med 188:17-27

25. Boomsma F, Veldhuisen DJ van, Kam PJ de et al. (1997) Plasma semicarbazide-sensitive amine oxidase is elevated in patients with congestive heart failure. Cardiovasc Res 33:387-391

26. Kurkijarvi R, Jalkanen S, Isoniemi H, Salmi M (2001) Vascular adhesion protein-1 (VAP-1) mediates lymphocyte-endothelial interactions in chronic kidney rejection. Eur J Immunol 31:2876-2884

27. Meszaros Z, Szombathy T, Raimondi L, Karadi I, Romics L, Magyar K (1999) Elevated serum semicarbazide-sensitive amine oxidase activity in non-insulin-dependent diabetes mellitus: correlation with body mass index and serum triglyceride. Metabolism 48:113-117

28. Weiss HG, Klocker J, Labeck B et al. (2003) Plasma amine oxidase: a postulated cardiovascular risk factor in nondiabetic obese patients. Metabolism 52:688-692

29. Hayes BE, Clarke DE (1990) Semicarbazide-sensitive amine oxidase activity in streptozotocin diabetic rats. Res Commun Chem Pathol Pharmacol 69:71-83

30. Boomsma F, Derkx FH, Meiracker AH van den, Man in 't Veld AJ, Schalekamp MA (1995) Plasma semicarbazidesensitive amine oxidase activity is elevated in diabetes mellitus and correlates with glycosylated haemoglobin. Clin Sci (Lond) 88:675-679

31. Boomsma F, Meiracker AH van den, Winkel S et al. (1999) Circulating semicarbazide-sensitive amine oxidase is raised both in type I (insulin-dependent), in type II (non-insulindependent) diabetes mellitus and even in childhood type I diabetes at first clinical diagnosis. Diabetologia 42:233-237

32. Salmi M, Stolen C, Jousilahti P et al. (2002) Insulin-regulated increase of soluble vascular adhesion protein-1 in diabetes. Am J Pathol 161:2255-2262
33. Garpenstrand H, Ekblom J, Backlund LB, Oreland L, Rosenqvist U (1999) Elevated plasma semicarbazide-sensitive amine oxidase (SSAO) activity in Type 2 diabetes mellitus complicated by retinopathy. Diabet Med 16:514521

34. Kurkijarvi R, Yegutkin GG, Gunson BK, Jalkanen S, Salmi M, Adams DH (2000) Circulating soluble vascular adhesion protein 1 accounts for the increased serum monoamine oxidase activity in chronic liver disease. Gastroenterology 119:1096-1103

35. Ahima RS, Flier JS (2000) Adipose tissue as an endocrine organ. Trends Endocrinol Metab 11:327-332

36. Bono P, Jalkanen S, Salmi M (1999) Mouse vascular adhesion protein 1 is a sialoglycoprotein with enzymatic activity and is induced in diabetic insulitis. Am J Pathol 155: 1613-1624

37. Moldes M, Feve B, Pairault J (1999) Molecular cloning of a major mRNA species in murine 3T3 adipocyte lineage. Differentiation-dependent expression, regulation, and identification as semicarbazide-sensitive amine oxidase. J Biol Chem 274:9515-9523

38. Morin N, Visentin V, Calise D et al. (2002) Tyramine stimulates glucose uptake in insulin-sensitive tissues in vitro and in vivo via its oxidation by amine oxidases. J Pharmacol Exp Ther 303:1238-1247

39. Guma A, Mora C, Santalucia T et al. (1992) System A transport activity is stimulated in skeletal muscle in response to diabetes. FEBS Lett 310:51-54

40. Fowler CJ, Tipton KF (1981) Concentration dependence of the oxidation of tyramine by the two forms of rat liver mitochondrial monoamine oxidase. Biochem Pharmacol 30: 3329-3332

41. Leung KH (1999) Release of soluble ICAM-1 from human lung fibroblasts, aortic smooth muscle cells, dermal microvascular endothelial cells, bronchial epithelial cells, and keratinocytes. Biochem Biophys Res Commun 260:734739

42. Morandini R, Ghanem G, Portier-Lemarie A, Robaye B, Renaud A, Boeynaems JM (1996) Action of cAMP on expression and release of adhesion molecules in human endothelial cells. Am J Physiol 270:H807-H816

43. Ferri C, Desideri G, Valenti M et al. (1999) Early upregulation of endothelial adhesion molecules in obese hypertensive men. Hypertension 34:568-573

44. Sage EH, Reed M, Funk SE et al. (2003) Cleavage of the matricellular protein SPARC by matrix metalloproteinase 3 produces polypeptides that influence angiogenesis. J Biol Chem 278:37849-37857

45. Tartare-Deckert S, Chavey C, Monthouel MN, Gautier N, Obberghen E van (2001) The matricellular protein SPARC/ osteonectin as a newly identified factor up-regulated in obesity. J Biol Chem 276:22231-22237 